\title{
High-fire-safety thermoplastic polyester constructed by novel sulfonate with benzimidazole structure
}

\author{
Wan-Shou Wu, Ping-Hui Duan, Yin-Long Wang, Li Chen, Xiu-Li Wang* and Yu-Zhong Wang*
}

\begin{abstract}
The flammability of thermoplastic polyesters and the subsequent heavy smoke and severe melt drips formed after ignition are the main obstacles hindering their widespread application. In this study, a novel ionic monomer containing sulfonate and benzimidazole was synthesized and incorporated into the main chain of poly(ethylene terephthalate) (PET, used as a model thermoplastic polyester) by melt copolymerization. The synergetic effect of ionic aggregation and carbonization endowed the obtained copolyester with high melt viscosity and excellent char-forming ability at high temperatures. The copolyester having a monomer content of $8 \mathrm{~mol}$.\% easily achieved the Underwriters Laboratories Inc 94 (UL-94) V-0 flammability rating without dripping and the limiting oxygen index value reached 33.0 vol.\%. In addition, the total smoke production, peak heat release rate, and maximum $\mathrm{CO}$ production decreased by $45.2 \%, 60.5 \%$, and $75.0 \%$, respectively, compared with those of PET. In addition, the copolyester was spinnable, and showed greater adsorption efficiency $(\mathbf{9 9 . 6 \% )}$ ) for a cationic dye from solution compared to PET (6.5\%), demonstrating the excellent affinity of the copolyester for the cationic dye. The obtained inherently firesafe PET copolyester has great potential for applications in flame retardant textiles, artwork base materials, and decorative materials for transportation applications.
\end{abstract}

Keywords: fire safety, thermoplastic polyester, cross-linking network, carbonization

\section{INTRODUCTION}

Currently, most commercial thermoplastic polymers exhibit high flammability, and their burning is accompanied by severe melt-dripping, which causes secondary damage. In addition, the toxic gases and thick smoke produced on combustion increase the lethality of fire-based accidents [1-4]. Thus, the development of polymeric materials with extremely high flame retardance, low smoke release, and low melt-dripping is urgently required. Many methods of achieving these resistant polymers have been proposed, and flame retardant additives, especially those containing halogens or phosphorus, have become the most widely used alternatives because of their high efficiency, low cost, and easy processing. However, the migration of these functional molecules from the substrate is inevitable, resulting in the loss of the fire suppression effect. In addition, halogen or phosphorus-containing monomers generally show high biotoxicity and can bioaccumulate, making them an environmental hazard [5-7]. Therefore, the design of polymers with intrinsic high fire safety is a promising alternative.

In general, the introduction of phosphorus-containing monomers into the backbones of polymers is the most efficient way to increase flame retardance [8-10]. However, a large amount of monomer is necessary because of its relatively low phosphorus content. In addition, this approach results in more serious melt drips, as well as the release of a large quantity of smoke and hazardous gases such as $\mathrm{CO}$ and $\mathrm{PH}_{3}$, which reduce survivability in firebased accidents [11-13]. The incorporation of monomers that enhance the char-forming ability of polymers is another widely used strategy. In this case, the obtained polymers can instantly form a stable char layer after ignition. Hence, the flames and drips are effectively suppressed. However, this strategy also shows low efficiency, and more than $15 \mathrm{~mol} \%$ of monomer is needed to achieve satisfactory results $[14,15]$.

As an alternative strategy, the concept of ionic aggregation has been proposed: this involves the introduction of ionic groups to the main chain of the polymer; the ionic groups are capable of forming ionic aggregates through electrostatic interactions. Specifically, the ionic

The Collaborative Innovation Center for Eco-Friendly and Fire-Safety Polymeric Materials (MoE), State Key Laboratory of Polymer Materials Engineering, National Engineering Laboratory of Eco-Friendly Polymeric Materials (Sichuan), College of Chemistry, Sichuan University, Chengdu 610064, China

*Corresponding authors (emails: xiuliwang1@163.com (Wang XL); yzwang@scu.edu.cn (Wang YZ)) 
groups in the main chains can spontaneously form a physical cross-linking network, leading to improved melt viscosity, which effectively retards the formation of melt drips and provides more time for the formation of stable char. Previous studies have concentrated on the use of phosphinate ionic groups, and polymers containing phosphinate show decreased flame and smoke release $[16,17]$. However, a high content of ionic monomers (at least $10 \mathrm{~mol} . \%$ ) is required, and the melt drips still form during combustion owing to the poor char-forming ability, so no examples of these polymers have achieved the UL-94 V-0 rating. Thus, focus has shifted to sulfonates, and researchers have found that polymers containing sodium sulfonate groups contain higher char residues and have lower heat release rate [18], so flame retardants containing sulfonate groups have the potential to reduce the fire hazard posed by polymers. In addition, benzimidazole was selected as a synergistic functional group to increase the char-forming ability and, thus, enhance the flame-retarding efficiency $[19,20]$.

We chose poly(ethylene terephthalate) (PET) as the substrate because of its inherent flammability, which is accompanied by severe melt dripping and the generation of toxic smoke on combustion. The sulfonate group and benzimidazole structure were combined for the first time, and the functional monomer sodium 3,5-bis(5-(methoxycarbonyl)-1H-benzoimidazol-2-yl) benzenesulfonate (BIS-Na) was synthesized and introduced into the PET chains. The sulfonate formed a stable physical crosslinking network in PET through electrostatic interactions. Because of the enhanced char-forming ability of the benzimidazole groups, the obtained copolyester exhibited excellent self-extinguishing and anti-dripping behavior, as well as smoke suppression ability, at a low monomer content. In addition, the melt rheological behavior, charforming ability, thermal transition behavior, fire safety, mechanical properties, spinnability, and affinity of cationic dye were extensively studied.

\section{EXPERIMENTAL SECTION}

\section{Chemical materials}

5-Sulfoisophthalic acid monosodium salt, ethylene glycol (EG, 99.0\%), methyl 3,4-diaminobenzoate, zinc acetate $\left(\mathrm{Zn}(\mathrm{OAc})_{2}, \mathrm{AR}\right)$, dimethyl terephthalate (DMT, $\left.\mathrm{CP}\right)$, 1,1,2,2-tetrachloroethane, $\quad N, N$-dimethylformamide (DMF), and 1-ethyl-3-(3-dimethylaminopropyl) carbodiimide hydrochloride (EDCI, 99.5\%) were obtained from Zhengzhou Alfachem Co., Ltd. Antimony trioxide $\left(\mathrm{Sb}_{2} \mathrm{O}_{3}\right.$, AR), 1-hydroxybenzotriazole (HOBt, 99.0\%), acetic acid, triethylamine (TEA, AR), and phenol were obtained from Shanghai EKEAR Bio@Tech Co., Ltd. (Shanghai, China).

\section{Preparation of BIS-Na}

Scheme 1a shows the synthesis of BIS-Na. In detail, $8.0 \mathrm{~g}$ 5-sulfoisophthalic acid monosodium salt, $500 \mathrm{~mL}$ DMF, $12.6 \mathrm{~g}$ EDCI, $9.0 \mathrm{~g} \mathrm{HOBt}, 11.0 \mathrm{~g}$ methyl-3,4-diaminobenzoate, and $8.5 \mathrm{~g}$ TEA were mixed in a 1 -L roundbottomed flask. The mixture was magnetically stirred overnight at room temperature, and then the solvent was evaporated and viscous liquid was obtained. Acetic acid $(500 \mathrm{~mL})$ was added, and the mixture was refluxed for $10 \mathrm{~h}$. The solid was precipitated, and the product was obtained by vacuum filtration. Finally, the product was

a

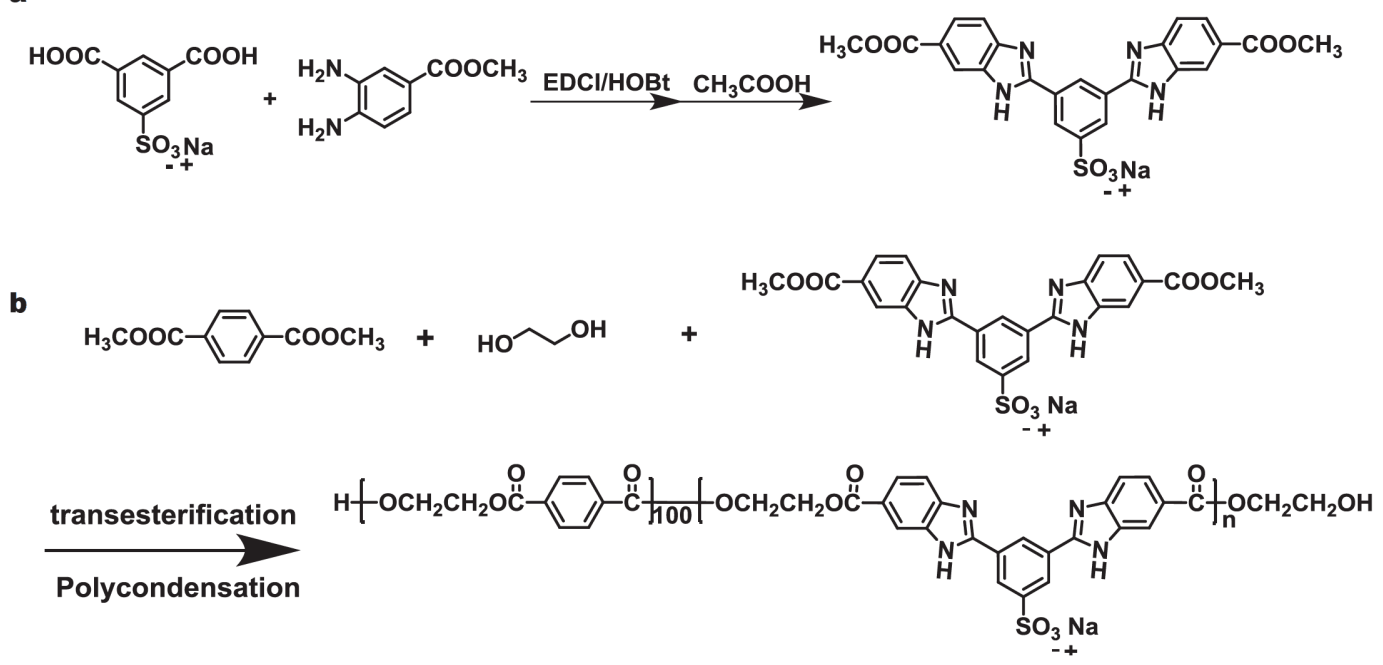

Scheme 1 Synthesis routes of (a) BIS-Na and (b) PETB-NaX. 
thoroughly dried until a constant weight was achieved.

BIS-Na: brown powder, $55 \%$ yield. ${ }^{1} \mathrm{H} \mathrm{NMR}\left(\mathrm{CF}_{3^{-}}\right.$ COOD- $d_{6}, 400 \mathrm{MHz}$ ) (Fig. S1a): Ar-H (9.49, 8.86, 8.55, 8.11), $-\mathrm{OCH}_{3}$ (4.23). ${ }^{13} \mathrm{C} \mathrm{NMR}\left(\mathrm{CF}_{3} \mathrm{COOD}-d_{6}, 100 \mathrm{MHz}\right)$ (Fig. $\mathrm{S} 1 \mathrm{~b}): \quad-\mathrm{C}=\mathrm{O} \quad(148.34), \quad-\mathrm{C}=\mathrm{N} \quad(146.26), \quad-\mathrm{C}-\mathrm{S}$ (134.22), -C-N (131.38), -C-NH (130.89), Ar-C (129.95, $129.44,124.33,116.59,114.40)$, -C-O (53.25). High-resolution mass spectrometry (HRMS) (electrospray ionization (ESI)): $\mathrm{C}_{24} \mathrm{H}_{17} \mathrm{~N}_{4} \mathrm{O}_{7} \mathrm{SNa}$. $[\mathrm{M}+\mathrm{H}]^{+}$Calcd: 529.0794, Found: 529.0806. X-ray photoelectron spectroscopy (XPS, Fig. S2): $\mathrm{Na}$ 1s $(1071.1 \mathrm{eV}), \mathrm{O}$ 1s $(532.1 \mathrm{eV}), \mathrm{N}$ 1s $(399.1 \mathrm{eV})$, C $1 \mathrm{~s}(284.5 \mathrm{eV})$, S $2 \mathrm{~s} \quad(231.4 \mathrm{eV}), \mathrm{S} 2 \mathrm{p}$ $(167.6 \mathrm{eV})$. Elemental analysis: calcd for $\mathrm{C}_{24} \mathrm{H}_{17} \mathrm{~N}_{4} \mathrm{O}_{7} \mathrm{SNa}$ : C, $54.54 \%$; H, 3.24\%; N, $10.61 \%$; S, $6.05 \%$; found: C, $54.95 \%$; H, 3.57\%; N, 10.24\%; S, 5.87\%.

\section{Preparation of copolyesters containing BIS-Na}

The synthesis of the PET copolyesters containing BIS-Na is shown in Scheme $1 \mathrm{~b}$, and the polymers are denoted PETB-NaX, where $X$ denotes the molar ratio of BIS-Na per hundred moles of DMT (BIS-Na:DMT $=X: 100)$. For example, PETB-Na3 was synthesized as follows: $19.4 \mathrm{~g}$ DMT, $14.3 \mathrm{~g}$ EG, $1.58 \mathrm{~g}$ BIS-Na, $0.02 \mathrm{~g} \mathrm{Zn(OAc)})_{2}$, and $0.01 \mathrm{~g} \mathrm{Sb}_{2} \mathrm{O}_{3}$ were mixed in a $100-\mathrm{mL}$ polymerization bottle. The mixture was transesterified at $190^{\circ} \mathrm{C}$ for $3 \mathrm{~h}$ with a mechanical stirrer under nitrogen flow. Then, the temperature of the system was maintained at $247^{\circ} \mathrm{C}$ and a pressure of $50 \mathrm{~Pa}$ for $2.5 \mathrm{~h}$. Thus, PETB-Na3 was obtained, and other samples were synthesized using the same process. Unmodified PET was synthesized as a control through similar esterification and melt polycondensation procedures.

\section{Characterization}

Thermogravimetric analysis (TGA) was performed using a NETZSCH 209 F1 instrument. The sample mass was maintained at $5.0 \pm 0.5 \mathrm{mg}$, and experiments were carried out in $\mathrm{Al}_{2} \mathrm{O}_{3}$ pans. The testing temperature range was $40-$ $700^{\circ} \mathrm{C}$ and the heating rate was $10^{\circ} \mathrm{C} \mathrm{min}{ }^{-1}$. X-ray diffraction (XRD) tests were performed on a Rigaku Ultima IV X-ray diffraction system. The original char residue of PETB-Na8 after cone calorimetry tests and the char residue heat-treated in air at $700^{\circ} \mathrm{C}$ were also analyzed.

The complex viscosities of PET and PETB-NaX were studied by TGA using a TA Discovery HR-2. Temperature scanning was carried out at 240, 255, 260, 265, and $310^{\circ} \mathrm{C}$, and the scanning frequency range was from 0.1 to $100 \mathrm{rad} \mathrm{s}^{-1}$ at $265^{\circ} \mathrm{C}$. The sample dimensions were $1 \mathrm{~mm}$ in thickness and $20 \mathrm{~mm}$ in diameter.

The Underwriters Laboratories Inc 94 (UL-94) rating tests were carried out using a CZF-2 apparatus, and the limiting oxygen index (LOI) values were determined using an HC-2C oxygen index flammability gauge. The sizes of the test samples were $130 \times 6.5 \times 3.2 \mathrm{~mm}^{3}$ and $130 \times 13 \times 3.2 \mathrm{~mm}^{3}$, and all samples were tested according to ASTM D 2863-97. An FTT (UK) calorimeter was used to perform the cone calorimetry tests. The heat flux was $50 \mathrm{~kW} \mathrm{~m}{ }^{-2}$, and all samples were measured according to ISO 5660-1. The testing sample size was $100 \times$ $100 \times 3.2 \mathrm{~mm}^{3}$. An FTT (UK) smoke density chamber was used to perform the smoke density tests. The heat flux was $50 \mathrm{~kW} \mathrm{~m}{ }^{-2}$, and all samples were measured according to ISO 5659 . The testing sample size was $75 \times 75$ $\times 3.2 \mathrm{~mm}^{3}$.

The water resistance of the copolyesters was evaluated according to $\mathrm{GB} / \mathrm{T} 11547-2008$. PETB-Na8 samples were immersed in water at $23 \pm 2^{\circ} \mathrm{C}$ for 1 or 2 weeks. The water-treated samples were completely dried, and then the UL-94 rating tests and LOI values were measured.

A NETZSCH 209 F1 TGA and Nicolet 6700 FTIR spectrophotometer were linked together for thermogravimetric (TG)-infrared (IR) spectrometry measurements. The testing temperature range was set from 40 to $700^{\circ} \mathrm{C}$, and the heating rate was $15^{\circ} \mathrm{C} \mathrm{min}{ }^{-1}$. Scanning electron microscopy (SEM) was performed on a JEOL JSM-5900LV instrument at a voltage of $10 \mathrm{kV}$. Energy dispersive X-ray (EDX) spectroscopy tests were carried out at an acceleration voltage of $15 \mathrm{kV}$. A Raman spectrometer (Lab RAM HR800, USA) was used to investigate the char, and the testing laser wavelength was $532 \mathrm{~nm}$.

An XSAM800 (Kratos, UK) X-ray photoelectron spectrometer was used to investigate the elemental contents and speciation of the char and was operated at $15 \mathrm{~mA}$ and $12 \mathrm{kV}$. An INSTRON F563-44 was used to investigate the mechanical properties of the samples. The crosshead speed was $5 \mathrm{~mm} \mathrm{~min}^{-1}$, and a $10 \mathrm{kN}$ load cell was used. The specimens were molded on dumbbell-shaped tensile bars with a thickness of $2.0 \pm 0.1 \mathrm{~mm}$ and width of $4.0 \pm$ $0.1 \mathrm{~mm}$. The spinnability of all samples was investigated with a high-pressure capillary rheometer (RG50, Gottfert) and a spinneret with a diameter of $0.5 \mathrm{~mm}$. An IKA mechanical agitator was used as the drafting device.

Small angle X-ray scattering (SAXS) was performed on a Xeuss 2.0 instrument (Xenocs Corporation, France) under vacuum at room temperature with a Dectris Pilatus detector. The samples were $1 \mathrm{~mm}$ in thick and $10 \mathrm{~mm}$ in diameter. The exposure time for each sample was $20 \mathrm{~min}$, and the sample-to-detector distance was $0.55 \mathrm{~m}$. The scattering vector ( $q$, Equation (1)) range of all the samples was $0.01-0.5 \AA^{-1}$. 
$q=\frac{(4 \pi \sin \theta)}{\lambda}=\frac{2 \pi}{d}$,

where, $\lambda$ is the wavelength, and $\theta$ is half the scattering angle. The SAXS data were reduced to remove the solvent background from the acquired sample scattering profiles using Foxtrot 3.2.7 and further analyzed by fitting to model expressions using SasView 4.1.2.

Differential scanning calorimetry (DSC) tests under nitrogen were performed using a TA Q200 DSC. All test sample weights were $5.0 \pm 0.5 \mathrm{mg}$, and the experiments were carried out in aluminum pans. The samples were heated to $275^{\circ} \mathrm{C}$, then cooled to $0^{\circ} \mathrm{C}$, and reheated to $275^{\circ} \mathrm{C}$. The heating and cooling rates were $10^{\circ} \mathrm{C} \mathrm{min}^{-1}$. The degrees of crystallinity $\left(X_{c}\right)$ of PET and PETB-NaX were obtained using Equation (2):

Crystallinity $(\%)=\frac{\Delta H_{\mathrm{f}}}{\Delta H_{\mathrm{f}}^{0}} \times 100 \%$,

where, $\Delta H_{\mathrm{f}}$ is the enthalpy of fusion of the sample $\left(\mathrm{J} \mathrm{g}^{-1}\right)$, and $\Delta H_{\mathrm{f}}^{0}$ is the enthalpy of fusion of the sample with $100 \%$ crystallinity $\left(140 \mathrm{~J} \mathrm{~g}^{-1}\right)$.

A UV-vis spectrophotometer (Cary 50, Agilent Technologies Co. Ltd) was used to determine the dye adsorption characteristics of the PET and PETB-NaX fibers. The fibers were pretreated with boiling water for $60 \mathrm{~min}$ to eliminate oil from the surface. After drying, the samples were dyed with $2 \mathrm{wt} . \%$ of cationic dye (methylene blue) in a $100-\mathrm{mL}$ round-bottomed flask. The liquor ratio was $1: 100$. The $\mathrm{pH}$ of the dye bath was maintained at 5.0 using a NaAc/HAc buffer system. The samples were immersed in the dye bath, and the temperature was increased from 30 to $95^{\circ} \mathrm{C}$ at a rate of $1{ }^{\circ} \mathrm{C} \mathrm{min}{ }^{-1}$ and then maintained for $2 \mathrm{~h}$. Finally, the dyed samples were removed from the dyebath and rinsed thoroughly [21,22]. The residual liquid in the bath and tap water was collected and diluted to $250 \mathrm{~mL}$. The maximum absorbances of the solutions were obtained at $\lambda=665 \mathrm{~nm}$ [23]. The adsorption efficiency $(\% \mathrm{E})$ was calculated using Equation (3):

$\% \mathrm{E}=\frac{A_{0}-A_{\mathrm{t}}}{A_{0}} \times 100(\%)$,

where, $A_{0}$ and $A_{\mathrm{t}}$ are the quantities of dye in the bath before and after dying [24].

\section{RESULTS AND DISCUSSION}

\section{Characterization of PETB-NaX}

FTIR, ${ }^{1} \mathrm{H}-\mathrm{NMR}$, and XPS measurements were performed to identify the structure of PETB-Na. Fig. S3 shows the FTIR spectra of BIS-Na, PET, and PETB-Na8. Unlike the
FTIR spectrum of PET, the spectra of BIS-Na and PETB$\mathrm{Na} 8$ contain two $\mathrm{N}-\mathrm{H}$ and $\mathrm{C}=\mathrm{N}$ bands $(3127$ and $1629 \mathrm{~cm}^{-1}$, respectively), which correspond to those groups in the benzimidazole ring [25]. This confirms the existence of BIS-Na units in PETB-Na8. Fig. S4a shows the ${ }^{1} \mathrm{H}$ NMR spectrum of PETB-Na8. The peaks at 9.40, $8.74,8.48,7.99$, and $7.84 \mathrm{ppm}$ can be assigned to the aryl protons of the BIS-Na units $\left(\mathrm{H}_{\mathrm{a}}, \mathrm{H}_{\mathrm{b}}, \mathrm{H}_{\mathrm{c}}, \mathrm{H}_{\mathrm{d}}\right.$, and $\left.\mathrm{H}_{\mathrm{e}}\right)$, whereas the two strong peaks at 8.25 and $4.95 \mathrm{ppm}$ can be ascribed to the DMT and EG units of PET $\left(\mathrm{H}_{\mathrm{f}}\right.$ and $\left.\mathrm{H}_{\mathrm{g}}\right)$. Fig. S4b shows the XPS spectrum of PETB-Na8. The $\mathrm{Na} 1 \mathrm{~s}$ peak of PETB-Na8 appears at $1070.9 \mathrm{eV}$, and the $\mathrm{N} 1 \mathrm{~s}, \mathrm{~S} 2 \mathrm{~s}$, and S 2p peaks appear at 401.2, 232.3, and $168.0 \mathrm{eV}$ respectively. These peaks show a slight shift compared with those of BIS-Na (Fig. S2) because of the changes in the chemical environment caused by polymerization. Combining these results, we can conclude that BIS-Na had been successfully introduced into the main chains of PETB-NaX.

By comparing the integral areas of the peaks at 8.55 and $8.24 \mathrm{ppm}\left(\mathrm{H}_{\mathrm{c}}\right.$ and $\left.\mathrm{H}_{\mathrm{f}}\right)$, which are related to the aryl protons of the monomer and DMT, respectively, the actual content of BIS-Na in PETB-NaX can be obtained, and the results are presented in Table S1. The theoretical BIS-Na content (molar fraction in the feed) is close to the actual BIS-Na content, suggesting that most of the BIS-Na was introduced to the PET chain. In addition, the intrinsic viscosity of PET is $0.67 \mathrm{dL} \mathrm{g}^{-1}$, whereas the intrinsic viscosity of PETB-Na3 is $0.80 \mathrm{dL} \mathrm{g}^{-1}$, which is attributed to the formation of ionic aggregates between polymer chains [26]. Further, increasing the content of BIS-Na to 5 and $8 \mathrm{~mol} \%$ resulted in a decrease in the intrinsic viscosities to 0.65 and $0.62 \mathrm{dL} \mathrm{g}^{-1}$, respectively. Gel permeation chromatography (GPC) was used to study the molecular weight and polymer dispersity index of the copolyesters, and the results are listed in Table S1. The weight-average molecular weight $\left(M_{\mathrm{w}}\right)$ and the number-average molecular weight $\left(M_{\mathrm{n}}\right)$ of PETB-NaX gradually decreased with increasing introduction of BIS$\mathrm{Na}$ owing to the low reactivity and steric hindrance of BIS-Na.

\section{Formation of ionic aggregates}

Generally, the ionic groups in polymers can form ionic aggregates via electrostatic interactions. The ion-rich domains can be observed as characteristic peaks in SAXS diffraction patterns [27]. The SAXS profiles of pure PET and PETB-NaX are shown in Fig. 1a. As can be seen in Fig. 1a, there is no peak in the SAXS profile of PET, suggesting that no ionic aggregates were formed. How- 

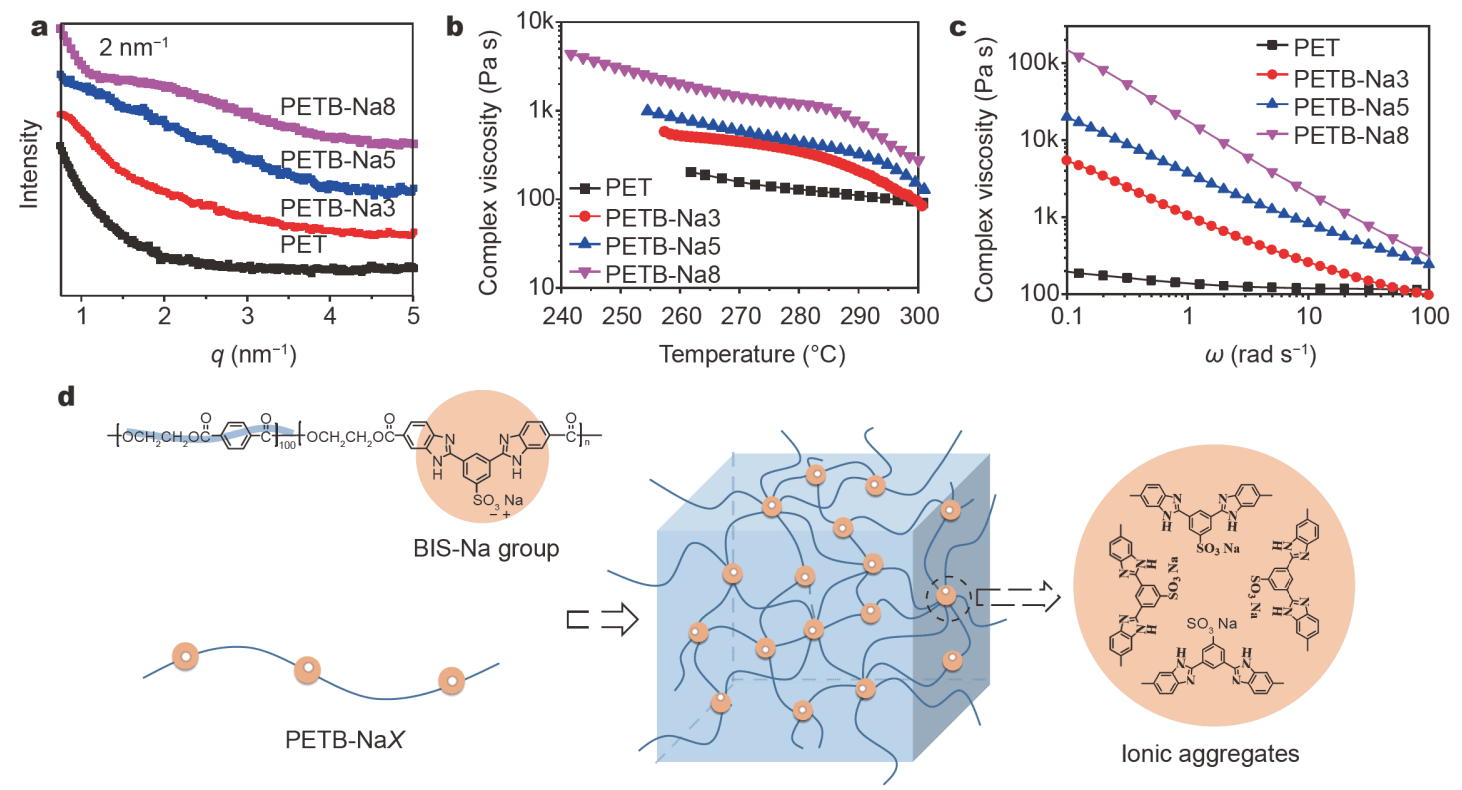

Figure 1 (a) SAXS, (b) complex viscosity-temperature and (c) complex viscosity-frequency curves of PET and PETB-NaX. (d) Simplified structure of PETB-NaX with ionic aggregates.

ever, a low-intensity peak is present in the profile of PETB-Na5. At higher BIS-Na contents, for example, 8 mol.\% in PETB-Na8, an obvious peak at $q=2 \mathrm{~nm}^{-1}$, a characteristic peak of ionic aggregates [28], was observed.

To demonstrate the formation of ionic aggregates in the copolyesters further, dynamic oscillatory rheological tests were employed. Fig. $1 \mathrm{~b}$ shows the curves of the temperature-dependent complex viscosities of PET and PETB-NaX. The complex viscosities of the copolyesters gradually increased with increase in BIS-Na content. The complex viscosities increased from $100 \mathrm{~Pa} \mathrm{~s}$ in PET to $3000 \mathrm{~Pa} s$ in PETB-Na8. Interestingly, the complex viscosities of PETB-NaX are higher than those of phosphitecontaining PET ionomers [29], illustrating the strongly restricted chain mobility [30]. It is worth mentioning that the complex viscosities of the copolyesters decreased slowly at lower temperatures (below $290^{\circ} \mathrm{C}$ ) but much faster at higher temperatures, meaning that the ionic aggregates play a governing role in increasing the melt viscosity of PETB-NaX at low temperatures. However, as the temperature increases above $290^{\circ} \mathrm{C}$, the ionic aggregates start to dissociate, leading to the accelerated reduction in the complex viscosity. However, the complex viscosity of PETB-Na8 at $300^{\circ} \mathrm{C}$ is still much higher than that of PET, suggesting a lower probability of melt dripping after ignition. The curves of the frequencydependent complex viscosity of PET and PETB-NaX are shown in Fig. 1c. Clearly, both PET and PETB-NaX ex- hibit shear thinning behavior with increasing frequency. The complex viscosities of PETB-NaX in the tested shear range are significantly higher than that of PET and gradually increase with increase in BIS-Na content.

Thus, the SAXS and complex viscosity results confirm the formation of ionic aggregates in the copolyesters, and these aggregates can be regarded as stable crosslinking points that limit the motion of the PET segments, leading to the high melt viscosity of PETB-NaX. A higher melt complex viscosity can effectively suppress the formation of melt drips and provide more time for char formation during combustion [31]. Thus, PETB-NaX may exhibit better anti-dripping performance and good char-formation properties. The simplified structure of PETB-NaX with ionic aggregates is shown in Fig. 1d.

\section{Char-forming ability}

The char-forming ability of the samples was examined by TGA in both nitrogen and air. Fig. 2a-d show the TGA and derivative thermogravimetry (DTG) curves. Table S2 lists the data in detail.

As shown in Fig. 2a, PET and PETB-NaX show onestep degradation in a nitrogen atmosphere. The temperature at which $5 \%$ mass loss occurred $\left(T_{5 \%}\right)$ of PETB$\mathrm{NaX}$ decreased from 367 to $354^{\circ} \mathrm{C}$ as the BIS-Na content was increased from 3 to $8 \mathrm{~mol} \%$., and the temperature at which the maximum mass loss occurred $\left(T_{\mathrm{d} \max }\right)$ showed the same trend. Notably, the amount of residue char of 

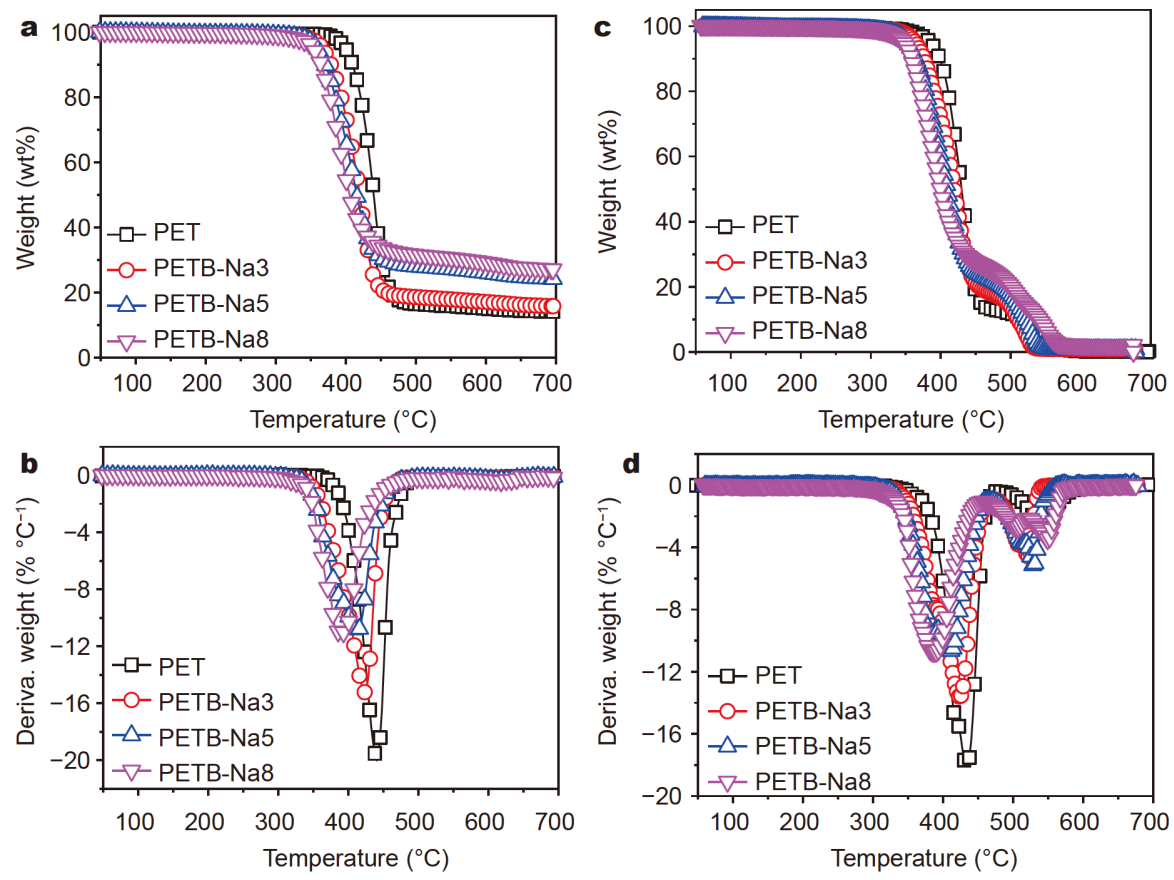

Figure 2 TGA and DTG curves of PET and PETB-NaX in (a, b) nitrogen and (c, d) air atmosphere.

PETB-Na8 at $700^{\circ} \mathrm{C}$ increased to 27 wt.\%, which is much higher than that of PET (11 wt.\%). This is related to the presence of ionic aggregates and the benzimidazole structure. The char can block the transportation of heat and combustible gaseous molecules, and the oxygen is inhibited at the same time.

PET and PETB-NaX show two decomposition processes in air: a major one $\left(340-480^{\circ} \mathrm{C}\right)$ and a minor one $\left(480-550^{\circ} \mathrm{C}\right)$, as shown in Fig. 2c. Compared with the data obtained in $\mathrm{N}_{2}$, the $T_{5 \%}$ values of PET and the copolyesters in air decreased, which is related to the presence of oxygen in the air. The $T_{5 \%}$ and the first maximum degradation temperature $\left(T_{\mathrm{d} \text { max } 1}\right)$ values also decreased with increase in BIS-Na content. However, the second maximum degradation temperature $\left(T_{\mathrm{d} \max 2}\right)$ increased from $522^{\circ} \mathrm{C}$ for PETB-Na3 to $550^{\circ} \mathrm{C}$ for PETB$\mathrm{Na} 8$, and the char residue also increased to $2 \mathrm{wt} . \%$. Thus, the TGA results indicate that BIS-Na can promote the formation of stable char during thermal degradation.

\section{Flame retardance measurement}

The flame retardance of PETB-NaX was studied using UL-94 burning and LOI tests. As shown in Fig. 3a, the LOI value of PET is 22.0 vol.\%. An obvious increasing trend can be observed after BIS-Na was introduced into the PET, and the LOI of PETB-Na8 reached 33.0 vol.\%. Fig. $3 \mathrm{~b}$ shows the pictures of the combustion of PET and
PETB-Na8. PET burns fiercely and generates serious melt drips after ignition at an oxygen concentration of 23.0 vol.\%. However, for PETB-Na8, a bulky intumescent char is rapidly formed after ignition at a much higher oxygen concentration of 33.0 vol.\%. This char layer covers the burning zone and acts as a stable char barrier. This barrier can effectively isolate heat and combustible gaseous products during combustion. Further, when the oxygen concentration was 33.0 vol.\%, PETB-Na8 quickly self-extinguished, and no melt-dripping was observed. Fig. $3 c$ shows the images of samples obtained from the LOI tests. PET suffered from severe melt-dripping and almost no char formed, whereas a stable char layer was observed and no melt-dripping behavior occurred for PETB-Na8.

In the UL-94 tests, PET formed severe drips, which ignited the absorbent cotton. This is because of its low melt viscosity and poor char-forming ability at high temperatures. However, PETB-Na3 and PETB-Na5 rapidly self-extinguished after ignition, and only a few melt drips were formed and ignited the cotton, thus achieving the UL-94 V-2 rating. PETB-Na8 formed a compact char layer and self-extinguished rapidly after the removal of the ignition source. Moreover, melt-dripping was completely suppressed; thus, it easily achieved a V-0 rating.

Combining the above results, we can conclude that the presence of BIS-Na in PET improved its melt viscosity 

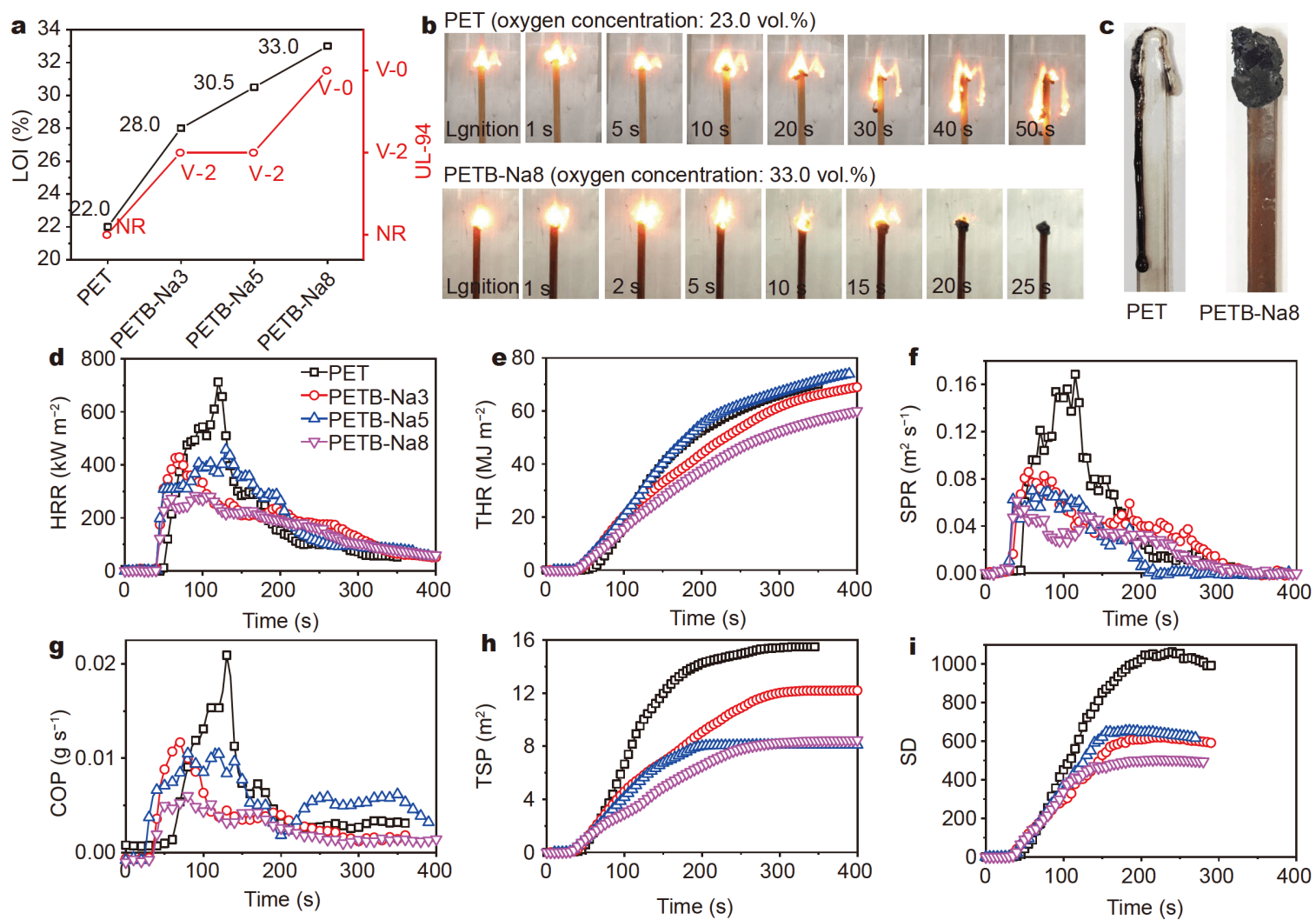

Figure 3 (a) UL-94 and LOI results of all samples. (b) LOI pictures of PET and PETB-Na8 with 23\% and 33\% oxygen concentrations, respectively. (c) PET (left) and PETB-Na8 (right) digital pictures after the LOI test. (d) HRR, (e) THR and (f) SPR, (g) COP, (h) TSP and (i) SD of the samples.

and carbonization during combustion, endowing it with significantly enhanced flame retardance and suppressing its melt-dripping behavior.

Cone calorimeter tests were performed to study the influence of BIS-Na on the flame retardance of PET in a realistic situation. Fig. $3 \mathrm{~d}-\mathrm{h}$ show the heat release rate (HRR), total heat release (THR), smoke producing rate (SPR), CO production (COP), and total smoke production (TSP) curves, respectively, obtained from the cone calorimeter tests. Fig. 3i shows the smoke density (SD) curves. Table S3 shows the related data.

As shown in Fig. 3d, the HRR curve of PET increases immediately to a peak without a plateau, corresponding to a non-charring material. However, the HRR curves of PETB-NaX show an initial increase until the formation of char. Then, the HRR decreases gradually as the char layer thickens, allowing us to classify them as a thermally thick charring samples [32]. In addition, for pure PET, the peak heat release rate (P-HRR) was found to be $734 \mathrm{~kW} \mathrm{~m}^{-2}$, demonstrating its high flammability hazard. However, PETB-Na3 has a much lower P-HRR of $428 \mathrm{~kW} \mathrm{~m}^{-2}$, which is $42 \%$ lower than that of PET. Further, the P-HRR value of PETB-Na8 was reduced to $290 \mathrm{~kW} \mathrm{~m}^{-2}$, a decrease of $60.5 \%$, indicating that BIS-Na significantly inhibits heat release. Fig. 3e shows the THR curves of PET and PETB-NaX. Compared with that of pure PET, the total heat release of PETB-Na8 is lower. As shown in Table S3, the THR values reduced from $70.5 \mathrm{MJ} \mathrm{m}^{-2}$ for pure PET to $60.8 \mathrm{MJ} \mathrm{m}^{-2}$ for PETB-Na8, which is a decrease of $14 \%$. Thus, PETB-NaX releases less heat at a lower rate during combustion.

Smoke and suffocation are the main causes of death by fire $[3,4]$. Moreover, polymers generate hazardous gases such as $\mathrm{CO}$ during combustion. Therefore, to evaluate the fire hazards of polymers accurately, the amount and toxicity of the released smoke should be measured. As shown in Fig. $3 \mathrm{f}$ and $\mathrm{g}$, the maximum SPR and COP values of PET surge to $0.17 \mathrm{~m}^{2} \mathrm{~s}^{-1}$ and $0.02 \mathrm{~g} \mathrm{~s}^{-1}$ after ignition, illustrating that pure PET releases a significant amount smoke and $\mathrm{CO}$ in a short time after combustion starts. However, the introduction of BIS-Na significantly suppressed the release of hazardous gaseous products, and the maximum SPR and COP values of PETB-Na8 were reduced to $0.06 \mathrm{~m}^{2} \mathrm{~s}^{-1}$ and $0.005 \mathrm{~g} \mathrm{~s}^{-1}$, respectively. 
Moreover, the TSP decreased with increasing BIS-Na content (Fig. 3h). The TSP values dropped from $15.5 \mathrm{~m}^{2}$ for PET to $8.5 \mathrm{~m}^{2}$ for PETB-Na8, representing a $45 \%$ reduction. The SPR, COP, and TSP results indicate that the introduction of BIS-Na effectively suppresses the smoke hazard of copolyesters.

In addition to toxic gases, smoke obscuration makes escape from fires difficult and is caused by the solid particles generated during combustion. A smoke density chamber is the most commonly used instrument for measuring the smoke production of polymers. During the test, the attenuation of light intensity caused by smoke was quantitatively measured, and the smoke density values were obtained [33]. As shown in Fig. 3i, PET produced a large amount of smoke at a high speed, and its maximum smoke density $\left(D_{\mathrm{m}}\right)$ reached 1068 , whereas PETB-Na3 yielded a much lower $D_{\mathrm{m}}$ of 622 . At a higher BIS-Na content of $8 \%$, the $D_{\mathrm{m}}$ decreased to $507,47.6 \%$ that of PET. Combining the SD and cone test results, clearly, the introduction of BIS-Na suppressed the amount and rate of release of hazardous gaseous products and solid particles from PET during combustion, and this could increase survivability in case of fire.

As shown in Table S3, PETB-Na8 generated 21.8 wt.\% residue char, which is much higher than PET (8.6 wt.\%). During combustion, the ionic aggregates endow copolyesters with much higher viscosities, providing more time for char layer formation. In addition, both sulfonate and benzimidazole can enhance the ability to form stable char, as discussed later.

The fire growth rate (FIGRA) values were calculated using the relationship FIGRA $=\mathrm{PHRR} / T_{\mathrm{PHRR}}$, where $T_{\text {PHRR }}$ indicates the time to P-HRR. A high FIGRA value means a short time to flashover and less time left for people to leave the fireground. The FIGRA values were reduced from $5.7 \mathrm{~kW} \mathrm{~m}^{-2} \mathrm{~s}^{-1}$ for PET to $3.4 \mathrm{~kW} \mathrm{~m}^{-2} \mathrm{~s}^{-1}$ for PETB-Na8, indicating that there would be more time to escape from the site of fire. In addition, the mean effective heat of combustion decreased from $16.8 \mathrm{MJ} \mathrm{kg}^{-1}$ for PET to $14.8 \mathrm{MJ} \mathrm{kg}^{-1}$ for PETB-Na8. These results strongly suggest that the copolyesters are extremely safe in a combustion environment.

\section{Flame retardance mechanism}

TG-IR measurements were performed to analyze the volatile products. Fig. 4 shows the 3D and FTIR spectra of the volatile molecules produced by the combustion of PET and PETB-Na8. Fig. 4a and b show the main gas products of the combustion of PET and PETB-Na8: $\mathrm{R}-\mathrm{O}-\mathrm{R}$, hydrocarbons, $\mathrm{RCHO}, \mathrm{RCOOH}, \mathrm{CO}$, and $\mathrm{CO}_{2}$.
These gaseous products are similar to those reported in the literature $[34,35]$. The main pyrolysis products of PET and PETB-Na8 are the same. The FTIR spectra show that PETB-Na8 starts to decompose at a lower temperature than PET (Fig. $4 \mathrm{c}$ and d), which is ascribed to its low $T_{5 \%}$ and $T_{\mathrm{d} \max }$ measured by TGA. Fig. 4e shows the FTIR spectra of PET and PETB-Na8 obtained at the temperature of maximum weight loss. Clearly, the combustion products of PETB-Na8 have the same characteristic IR bands as those of PET, confirming that both produce the same pyrolysis products. In contrast, BIS-Na remains in the solid phase, suggesting a solid-phase flame retarding mechanism.

XPS was used to study the residual char produced by untreated PETB-Na8 and that treated at different temperatures (heated to 350,400 , and $450^{\circ} \mathrm{C}$ in $\mathrm{N}_{2}$ for $10 \mathrm{~min}$ ). Table S4 lists the data in detail. Because the sulfur content was too low to be detected, we used the $\mathrm{C}$ 1s spectra for further analysis, and the C 1s XPS spectra of PETB-Na8 are shown in Fig. $4 \mathrm{f}-\mathrm{i}$. Three peaks corresponding to $\mathrm{C}=\mathrm{C} / \mathrm{C}-\mathrm{C}, \mathrm{C}=\mathrm{N} / \mathrm{C}-\mathrm{O}$ and $\mathrm{C}-\mathrm{N}$, and $\mathrm{C}=\mathrm{O}$ at 284.6, 285.9, and $288.8 \mathrm{eV}$, respectively, were used for analysis [36]. The $\mathrm{C}=\mathrm{O}$ peak was smaller after heating, which was attributed to the decarboxylation of polyesters. The $\mathrm{C} / \mathrm{O}$ ratios of the treated specimens increased from 3.42 to 7.92 , indicating the carbonization and aromatization processes accompanied by decarboxylation.

Fig. S5 shows the N 1s XPS spectra of PETB-Na8 before and after heat treatment. Two peaks at 398.2 and $400.4 \mathrm{eV}$ were observed, which correspond to pyridine-like nitrogen $(-\mathrm{C}=\mathrm{N})$ and pyrrole-like nitrogen $(-\mathrm{C}-\mathrm{N})$, respectively. As shown in Table S4, the nitrogen content of PETB-Na8 was increased after heating, suggesting that nitrogen is retained in the solid phase during degradation and facilitates the formation of nitrogen-containing residue char [37].

Fig. 5a-d show SEM images of the morphology of PET and PETB-NaX chars obtained from the cone calorimetry tests. In the image of the PET char showing the outer surface, it can be seen that the char layer is fragile, loose, and porous. This structure cannot stop the inner material from burning (Fig. 5a). In contrast, the surfaces of PETB$\mathrm{NaX}$ are compact and rough (Fig. $5 \mathrm{~b}_{1}-\mathrm{d}_{1}$ ). In addition, as shown in Fig. $5 d_{1}$, there are many bumps distributed on the outer surface of the PETB-Na8 char, probably caused by unreleased gaseous products. These observations suggest that the char layer has an extraordinary isolating effect. The EDX results (Table S5) indicate that the atomic concentration of nitrogen in the char is higher than that of the original copolyesters, likely because the 

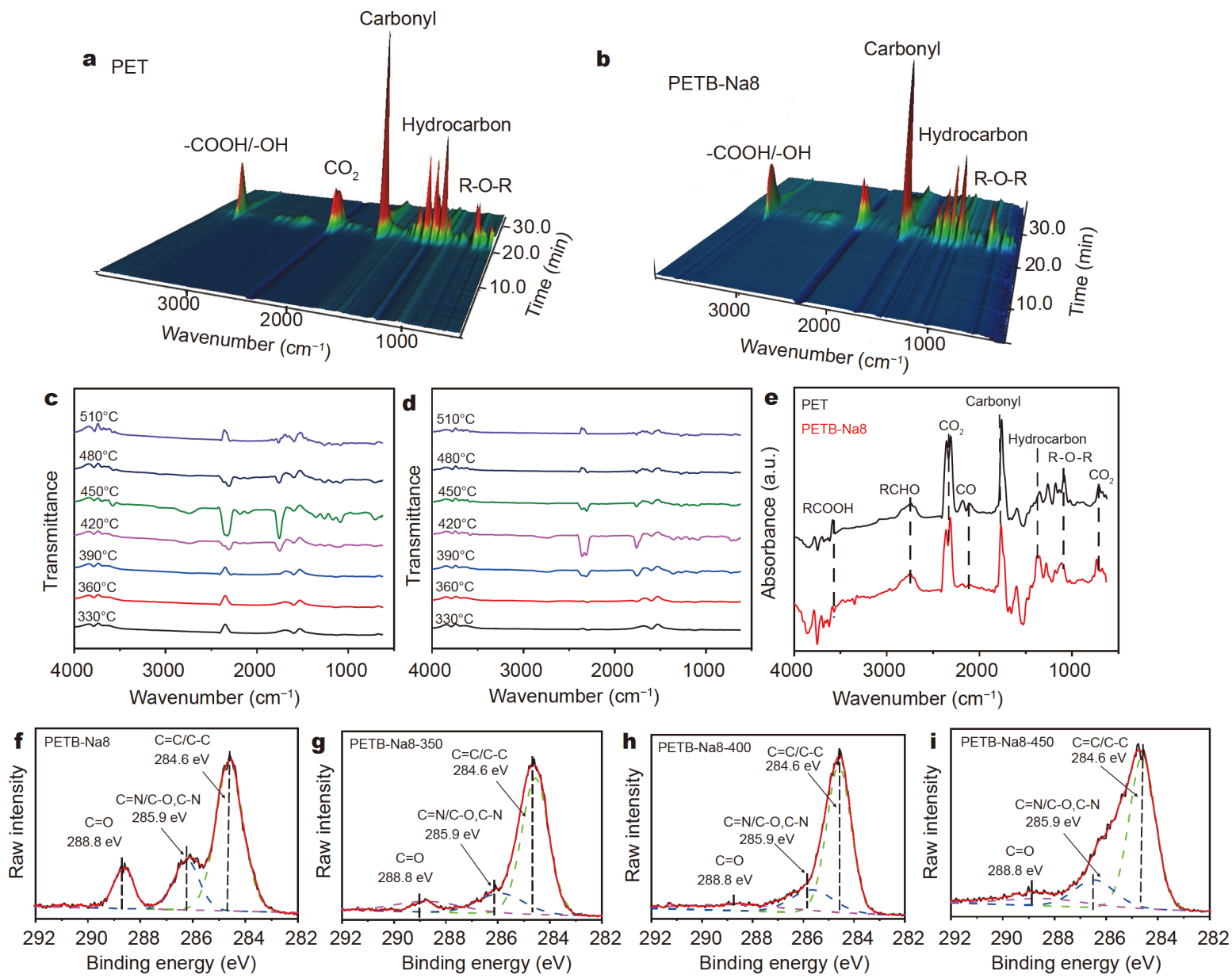

Figure 4 3D pictures and FTIR spectra of the volatile molecules of (a, c) PET, (b, d) PETB-Na8. (e) FTIR spectra of PET and PETB-Na8 when maximum weight loss occur. ( $\mathrm{f}-\mathrm{i}) \mathrm{C} 1 \mathrm{~s}$ XPS spectra of PETB-Na8 before and after heat treatment.

BIS-Na component facilitates the formation of a stable nitrogen-containing char layer during combustion. These char layers play an important role in heat insulation and smoke inhibition. Therefore, the majority of gaseous decomposition products and solid particles are retained in the solid phase. We also noticed that there were many nanosheets and nanowires distributed on the char surfaces of copolyesters, which is due to the migration of sodium sulfonate ionic groups during combustion, as confirmed from the higher atomic concentrations of oxygen and sodium in this region (Table S5). These nanoscale sheets and wires have high boiling points and adhere to the surface of the char layer, acting as a physical barrier. To study the nanoscale sheets and wires, XRD measurements of the char residue of PETB-Na8 were carried out. As shown in Fig. S6, the original char residue showed diffraction peaks $(2 \theta)$ at $\sim 31.8^{\circ}, 34.0^{\circ}$, and $\sim 37.8^{\circ}$, which originate from sodium sulfate $\left(\mathrm{Na}_{2} \mathrm{SO}_{4}\right)$. In addi- tion, we also treated the char residue at $700^{\circ} \mathrm{C}$, and the XRD results also clearly indicate the presence of $\mathrm{Na}_{2} \mathrm{SO}_{4}$. Combining the above results, the sodium sulfonate ionic groups of BIS-Na was converted to $\mathrm{Na}_{2} \mathrm{SO}_{4}$ during combustion, which covered the char surface and further enhanced the isolating effect of the char layer.

The char was also analyzed using Raman spectroscopy. As shown in Fig. 5, the spectra contain two clear peaks at 1587 and $1340 \mathrm{~cm}^{-1}$ (G and D bands of graphitic structures). The $G$ band represents ordered graphitic char, whereas the D band represents disordered carbon. Generally, a large ratio of the $\mathrm{D}$ and $\mathrm{G}$ band peak areas $\left(I_{\mathrm{D}} / I_{\mathrm{G}}\right)$ indicates small microcrystalline domains, suggesting that the char layer is more compact. The $I_{\mathrm{D}} / I_{\mathrm{G}}$ values of PET and PETB-NaX increase in the order: PET $(1.73)<$ PETBNa3 (2.16) < PETB-Na5 (2.58) < PETB-Na8 (2.76), indicating that the char becomes more compact with increasing BIS-Na content. Therefore, based on the above 

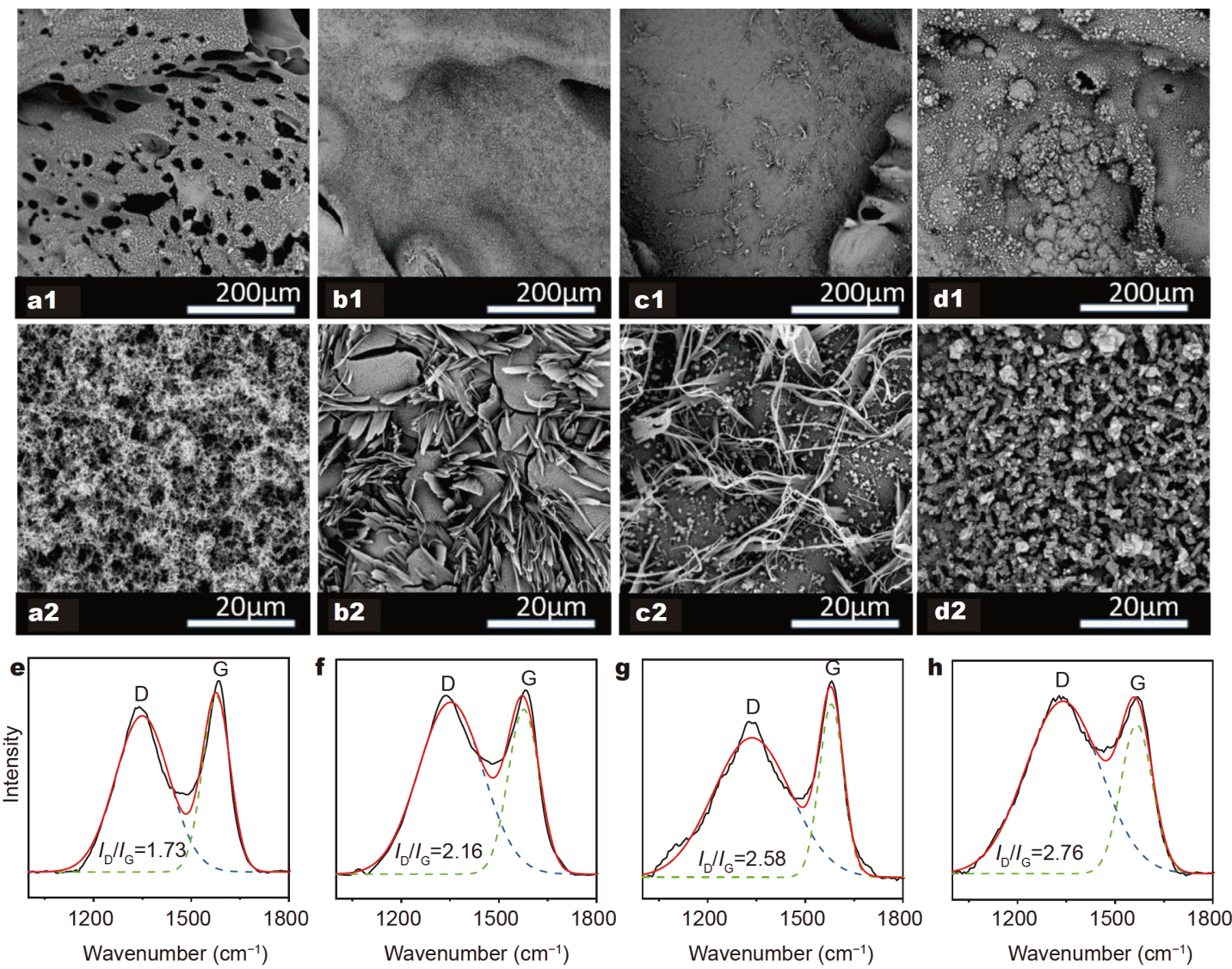

Figure 5 SEM $(500 \times, 5000 \times)$ pictures and Raman spectra of the char: $\left(a_{1}, a_{2}, e\right)$ pure PET; $\left(b_{1}, b_{2}, f\right)$ PETB-Na3; $\left(c_{1}, c_{2}, g\right)$ PETB-Na5; (d $\left.d_{1}, d_{2}, h\right)$ PETBNa8.

results, we can deduce that the flame suppression of PETB-NaX occurs via a solid-phase mechanism, which is clearly shown in Fig. 6.

\section{Thermal transition behavior}

The thermal behavior of PETB-NaX was studied by DSC. Fig. $7 \mathrm{a}$ and $\mathrm{b}$ show the second heating and first cooling curves of PET and PETB-NaX. Table S1 lists these data in detail. The glass transition temperature $\left(T_{\mathrm{g}}\right)$ is the temperature at which a material changes from a glassy state to a rubbery state, and the polymer chains start to move at this temperature. From Table S1, we can see that the $T_{\mathrm{g}}$ of PETB-NaX shifts to higher temperatures compared with that of PET. The $T_{\mathrm{g}}$ increased to $80^{\circ} \mathrm{C}$ when the BIS-Na content was $3 \mathrm{~mol} \%$, and those of PETB-Na5 and PETB$\mathrm{Na} 8$ increased to 86 and $88^{\circ} \mathrm{C}$, respectively. Normally, the $T_{\mathrm{g}}$ value increases with increasing intermolecular interactions or cross-linking [35]. The increasing values of $T_{\mathrm{g}}$ reflect the formation of physical cross-links, which restrict the mobility of the chain segments of the copolyesters.
As shown in Fig. 7a, the crystallization peaks become broader and lower with increasing BIS-Na content, and the crystallization temperature $\left(T_{\mathrm{c}}\right)$ shifts to lower temperatures in the cooling scan. For PETB-Na8, the crystallization peak disappears. In the heating scan, the cooling crystallization temperature $\left(T_{\mathrm{cc}}\right)$ showed the same trend as in the heating process. Compared with those of pure PET, the melting point $\left(T_{\mathrm{m}}\right)$ and corresponding enthalpy $\left(\Delta H_{\mathrm{m}}\right)$ of the copolyesters gradually decrease from $249^{\circ} \mathrm{C}$ and $38.7 \mathrm{~J} \mathrm{~g}^{-1}$ for PETB-Na3 to $228^{\circ} \mathrm{C}$ and $9.1 \mathrm{~J} \mathrm{~g}^{-1}$ for PETB-Na8. Accordingly, the values of $X_{c}$ calculated using Equation (2) decrease from 30.5\% for PET to $6.5 \%$ for PETB-Na8. These results illustrate that the physical crosslinking caused by the ionic aggregates restricts the mobility of PET chains, which leads to a reduction in the crystallizability. The introduction of the bulk structure of BIS-Na into the backbone of PET breaks the regularity of the PET main chain and reduces the crystallizability. Notably, when the BIS-Na content was $8 \mathrm{~mol} \%$, an obvious melting peak was observed in the second heating scan (Fig. 7b). This phenomenon suggests 


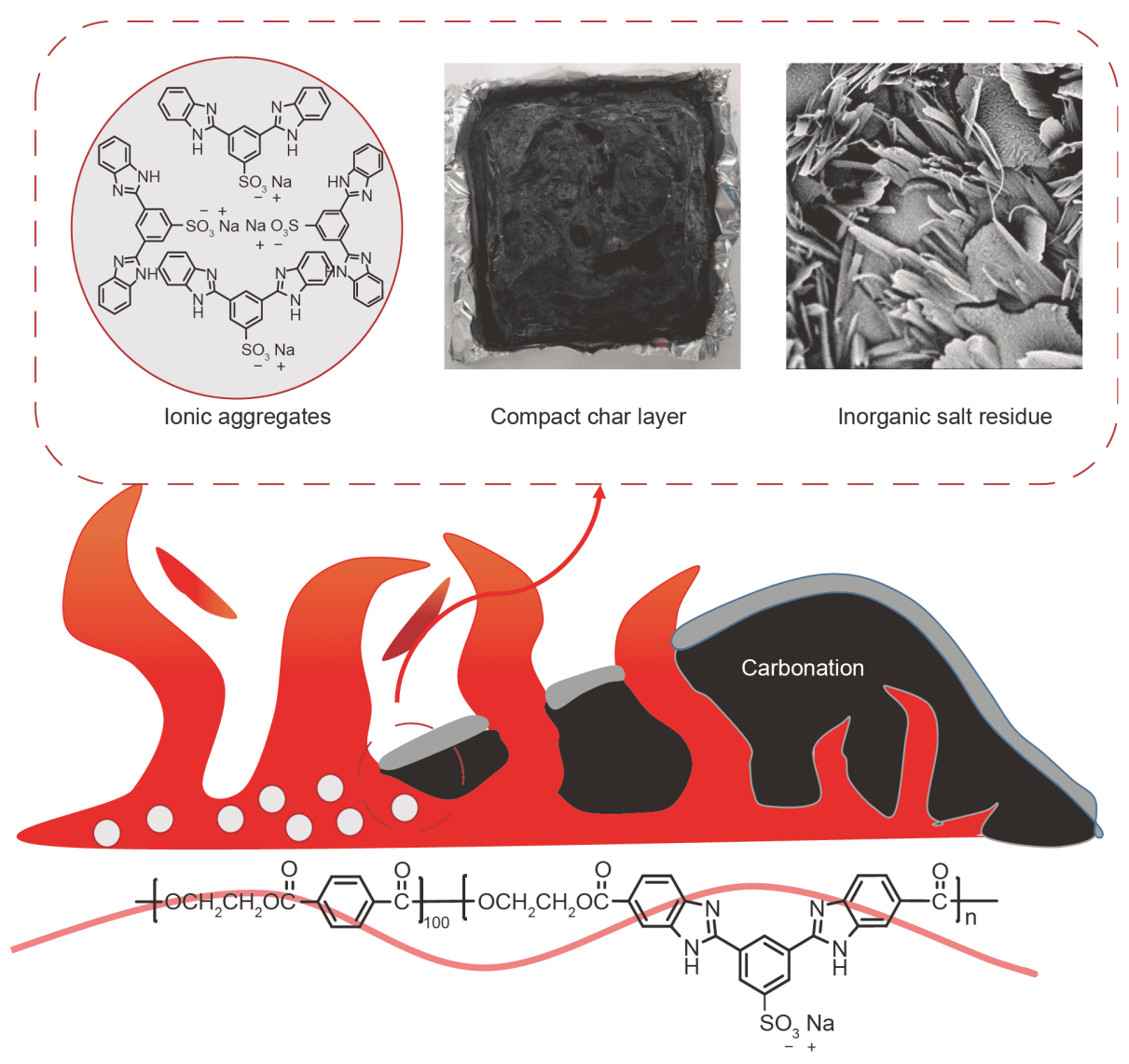

Figure 6 Proposed flame retardant mechanism of PETB-NaX.

that the copolyesters retain good crystallizability, better than that of phosphate-containing PET ionomers [29].

\section{Mechanical properties and water resistance}

The mechanical properties of PET and PETB-NaX were studied by tensile testing. The stress-strain curves are shown in Fig. 7c. As shown in Fig. 7c, the tensile strength of PET is $56 \mathrm{MPa}$. After BIS-Na was incorporated, the tensile strengths were reduced to 48,42 , and $36 \mathrm{MPa}$ for PETB-Na3, PETB-Na5, and PETB-Na8, respectively. In addition, the elongation at break of PETB-NaX also decreased. This result indicates that the introduction of BIS$\mathrm{Na}$ led to a reduction in the mechanical properties of PET, which may be ascribed to the poor crystallinity and low molecular weight of PETB-NaX. Thus, in future work, we plan to increase the molecular weight of PETB$\mathrm{NaX}$. However, PETB-Na8 still has the same tensile strength as poly(butylene succinate) [38], which is used as a packaging and textile material $[39,40]$, suggesting that PETB-Na8 is a promising high-quality polyester. In addition, the water resistance of PETB-Na8 was studied. As shown in Fig. S7, PETB-Na8 kept the UL-94 V-0 rating after 1 week immersion, and the LOI value was $32.5 \mathrm{vol} . \%$. Upon further increasing the water treatment time to 2 weeks, PETB-Na8 still achieved the UL-94 V-0 rating, and the LOI value was 31.5 vol.\%, suggesting that the copolyesters have good water resistance.

\section{Spinnability and dye adsorption efficiency}

We also studied the spinnability of PETB-NaX. As shown in Fig. 7d. PETB-Na8 formed yellow fibers when spun through a high-pressure capillary rheometer, and the SEM image shows that the surface of the obtained fiber was smooth. The digital and SEM images of the PETBNa3 fibers and PETB-Na5 fibers are shown in Fig. S8. The results suggest that PETB-NaX has good potential for textile applications. The dyeability of the obtained fibers of pure PET and PETB-NaX was investigated by studying the dye adsorption efficiency (\%E). The UV absorbance curves and \%E results are shown in Fig. $7 \mathrm{e}$ and $\mathrm{f}$, respectively. As shown in Fig. 7e, all samples exhibited the highest absorbance at $665 \mathrm{~nm}$. The absorbance values of pure methylene blue and the PET dye bath were 5.55 and 5.19, respectively; using Equation (3), the \%E of PET was 

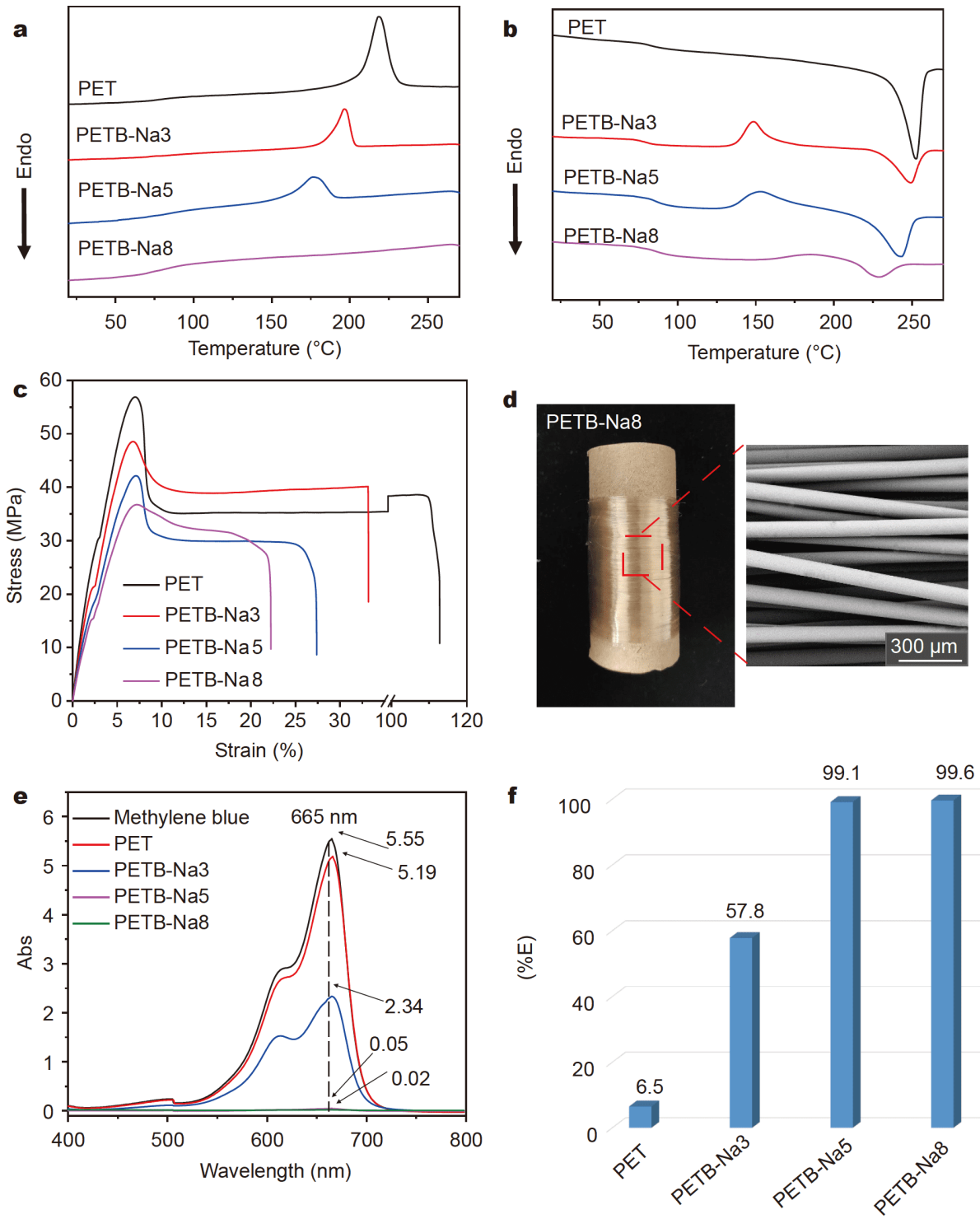

Figure 7 DSC curves of PETB-NaX: (a) the first cooling and (b) the second heating scans; (c) stress-strain curves. (d) Digital and SEM image of PETB-Na8 fiber. (e) Absorbance curves and (f) \%E of different samples.

found to be $6.5 \%$ (Fig. 7f). This result indicates that only $6.5 \%$ of the total methylene blue in the dye bath was adsorbed on the PET fibers, suggesting the weak affinity of the cationic dye for PET. However, for PETB-Na3, the absorbance was 2.34 , and the $\% \mathrm{E}$ increased to $57.8 \%$, an increase of $790 \%$ compared with that of PET. At higher BIS-Na contents $(8 \mathrm{~mol} \%)$, the absorbance value was reduced further (0.02), yielding an $\% \mathrm{E}$ of $99.6 \%$, indicating that almost all the cationic dye in the dye bath was adsorbed in the PETB-Na8 fiber. There are three reasons for the increased \%E: strong electrostatic interactions and hydrogen bonds between BIS-Na and the cationic dye and the decreasing crystallinity of PET and, thus, greater number of amorphous regions in PETB$\mathrm{NaX}$, which facilitate the diffusion and adsorption of the dye.

The above results suggest that PETB-NaX is spinnable and has excellent affinity for cationic dyes. Thus, these novel polymers suggest a route to improve the cationic dyeability of copolyester fibers, and we plan to study the cationic dyeability of PETB-NaX further.

\section{CONCLUSION}

In this study, we designed and synthesized a sulfonate 
functional monomer, and introduced this monomer into PET chains through melt polycondensation. The sulfonate group of BIS-Na forms ionic aggregates, which act as a physical cross-linking network. Combined with the high char-forming property of the benzimidazole structure, BIS-Na endows PETB-NaX with high melt viscosity and excellent char-forming ability. Consequently, PETB-NaX showed significantly enhanced flame retardance and suppressed smoke and dripping hazards during combustion. When the BIS-Na content was $8 \mathrm{~mol} \%$, the corresponding copolymer, PETB-Na8, had a much higher LOI than PET (33\%) and easily achieved the UL-94 V-0 rating. In addition, the significantly decreased PHRR, THR, TSP, COP, and $D_{\mathrm{m}}$ values indicate that the PETB$\mathrm{NaX}$ copolyesters show significant flame retarding and smoke suppressing effect during burning. Thus, PETB$\mathrm{NaX}$ form compact char quickly after ignition, which effectively isolates the transmission of heat and combustible products, resulting in a profound solid-phase flame retardant mechanism. Furthermore, the obtained copolyesters showed great spinnability, and the dye adsorption efficiency of a cationic dye increased from 6.5\% (PET) to 99.6\% (PETB-Na8), suggesting excellent affinity for the cationic dye. In summary, the addition of a small amount of BIS-Na to the main chain of PET endows it with high fire safety, making this new copolyester a promising candidate for future polymer applications.

Received 9 October 2020; accepted 5 January 2021; published online 11 March 2021

1 Chen L, Zhao HB, Ni YP, et al. 3D printable robust shape memory PET copolyesters with fire safety via $\pi$-stacking and synergistic crosslinking. J Mater Chem A, 2019, 7: 17037-17045

2 Liu BW, Chen L, Guo DM, et al. Fire-safe polyesters enabled by end-group capturing chemistry. Angew Chem Int Ed, 2019, 58: 9188-9193

3 Yan YW, Chen L, Jian RK, et al. Intumescence: An effect way to flame retardance and smoke suppression for polystryene. Polym Degradation Stability, 2012, 97: 1423-1431

4 Chen L, Wu JN, Ni YP, et al. Contribution of phenylimide to flame retardancy, anti-dripping and smoke suppression of PET. Acta Polym Sin, 2017, 7: 1207-1214

5 Alongi J, Han Z, Bourbigot S. Intumescence: tradition versus novelty. A comprehensive review. Prog Polym Sci, 2015, 51: 28-73

6 Yang W, Song L, Hu Y, et al. Enhancement of fire retardancy performance of glass-fibre reinforced poly(ethylene terephthalate) composites with the incorporation of aluminum hypophosphite and melamine cyanurate. Compos Part B-Eng, 2011, 42: 10571065

7 Blum A, Gold MD, Ames BN, et al. Children absorb tris-BP flame retardant from sleepwear: urine contains the mutagenic metabolite, 2,3-dibromopropanol. Science, 1978, 201: 1020-1023

8 Wang LS, Wang XL, Yan GL. Synthesis, characterisation and flame retardance behaviour of poly(ethylene terephthalate) copolymer containing triaryl phosphine oxide. Polym Degrad Stabil, 2000, 69: $127-130$

9 Chang SJ, Chang FC. Sequential distribution of copolyesters containing the phosphorus linking pendant groups characterized by ${ }^{1}$ H-N.M.R.. Polymer, 1998, 39: 3233-3240

10 Chang SJ, Sheen YC, Chang RS, et al. The thermal degradation of phosphorus-containing copolyesters. Polym Degrad Stabil, 1996, 54: $365-371$

11 Chen HB, Zhang Y, Chen L, et al. A main-chain phosphoruscontaining poly(trimethylene terephthalate) copolyester: synthesis, characterization, and flame retardance. Polym Adv Technol, 2012, 23: $1276-1282$

12 Chen HB, Zhang Y, Chen L, et al. Novel inherently flame-retardant poly(trimethylene terephthalate) copolyester with the phosphoruscontaining linking pendent group. Ind Eng Chem Res, 2010, 49: 7052-7059

13 Sato M, Endo S, Araki Y, et al. The flame-retardant polyester fiber: Improvement of hydrolysis resistance. J Appl Polym Sci, 2000, 78: 1134-1138

$14 \mathrm{Fu} \mathrm{T}$, Guo DM, Chen L, et al. Fire hazards management for polymeric materials via synergy effects of pyrolysates-fixation and aromatized-charring. J Hazard Mater, 2020, 389: 122040

15 Ni YP, Li QT, Chen L, et al. Semi-aromatic copolyesters with high strength and fire safety via hydrogen bonds and $\pi-\pi$ stacking. Chem Eng J, 2019, 374: 694-705

16 Ge XG, Wang C, Hu Z, et al. Phosphorus-containing telechelic polyester-based ionomer: Facile synthesis and antidripping effects. J Polym Sci A Polym Chem, 2008, 46: 2994-3006

17 Zhang Y, Chen L, Zhao JJ, et al. A phosphorus-containing PET ionomer: from ionic aggregates to flame retardance and restricted melt-dripping. Polym Chem, 2014, 5: 1982-1991

18 Deans T, Schiraldi DA. Flammability of polyesters. Polymer, 2014, 55: 2825-2830

19 Wang Y, Yuan Y, Zhao Y, et al. Flame-retarded epoxy resin with high glass transition temperature cured by DOPO-containing $H$ benzimidazole. High Performance Polyms, 2016, 29: 94-103

$20 \mathrm{Ni}$ YP, Wu WS, Chen L, et al. How hydrogen bond interactions affect the flame retardancy and anti-dripping performances of PET. Macromol Mater Eng, 2020, 305: 1900661

21 Makhlouf C, Ladhari N, Roudesli S, et al. Influence of grafting with acrylic acid on the dyeing properties of polyamide 6.6 fibres. Coloration Tech, 2012, 128: 176-183

22 Son $\mathrm{Y}$, Hong J, Lim H, et al. A study of heterobifunctional reactive dyes on nylon fibers: dyeing properties, dye moiety analysis and wash fastness. Dyes Pigments, 2005, 66: 231-239

23 Sultan M, Javeed A, Uroos M, et al. Linear and crosslinked Polyurethanes based catalysts for reduction of methylene blue. J Hazard Mater, 2018, 344: 210-219

24 Xiong LK, Fu YF, Zhang SY, et al. Investigation of stain-resistant cationic dyeable nylon 6 modified with sodium salt of 5-sulfoisophthalic acid and polyethylene glycol. Fibers Polym, 2016, 17: 984-991

25 Hu D, Wang G, Feng J, et al. Exploring supramolecular selfassembly of a bisamide nucleating agent in polypropylene melt: The roles of hydrogen bond and molecular conformation. Polymer, 2016, 93: 123-131

26 Berti C, Colonna M, Binassi E, et al. Telechelic ionomeric poly(butylene terephthalate): Synthesis, characterization and comparison with random ionomers. Reactive Funct Polyms, 2010, 70: $366-375$ 
27 Wang W, Tudryn GJ, Colby RH, et al. Thermally driven ionic aggregation in poly(ethylene oxide)-based sulfonate ionomers. J Am Chem Soc, 2011, 133: 10826-10831

28 Li N, Leng Y, Hickner MA, et al. Highly stable, anion conductive, comb-shaped copolymers for alkaline fuel cells. J Am Chem Soc, 2013, 135: 10124-10133

29 Zhang Y, Ni YP, He MX, et al. Phosphorus-containing copolyesters: The effect of ionic group and its analogous phosphorus heterocycles on their flame-retardant and anti-dripping performances. Polymer, 2015, 60: 50-61

30 Eisenberg A, Hird B, Moore RB. A new multiplet-cluster model for the morphology of random ionomers. Macromolecules, 1990, 23: 4098-4107

31 Wang JS, Zhao HB, Ge XG, et al. Novel flame-retardant and antidripping branched polyesters prepared via phosphorus-containing ionic monomer as end-capping agent. Ind Eng Chem Res, 2010, 49: 4190-4196

32 Schartel B, Hull TR. Development of fire-retarded materialsInterpretation of cone calorimeter data. Fire Mater, 2007, 31: 327354

33 Babrauskas V. Effective measurement techniques for heat, smoke, and toxic fire gases. Fire Saf J, 1991, 17: 13-26

34 Deng Y, Zhao CS, Wang YZ. Effects of phosphorus-containing thermotropic liquid crystal copolyester on pyrolysis of PET and its flame retardant mechanism. Polym Degrad Stabil, 2008, 93: 20662070

$35 \mathrm{Wu}$ JN, Chen L, Fu T, et al. New application for aromatic Schiff base: High efficient flame-retardant and anti-dripping action for polyesters. Chem Eng J, 2018, 336: 622-632

$36 \mathrm{Fu}$ T, Zhao X, Chen L, et al. Bioinspired color changing molecular sensor toward early fire detection based on transformation of phthalonitrile to phthalocyanine. Adv Funct Mater, 2019, 29: 1806586

37 Song $\mathrm{P}, \mathrm{Xu} \mathrm{Z}$, Lu Y, et al. Bio-inspired hydrogen-bond cross-link strategy toward strong and tough polymeric materials. Macromolecules, 2015, 48: 3957-3964

38 Dai X, Qiu Z. Synthesis and properties of novel biodegradable poly (butylene succinate-co-decamethylene succinate) copolyesters from renewable resources. Polym Degrad Stabil, 2016, 134: 305-310

39 Zeng JB, Huang CL, Jiao L, et al. Synthesis and properties of biodegradable poly(butylene succinate-co-diethylene glycol succinate) copolymers. Ind Eng Chem Res, 2012, 51: 12258-12265

40 Shi XQ, Aimi K, Ito $\mathrm{H}$, et al. Characterization on mixed-crystal structure of poly(butylene terephthalate/succinate/adipate) biodegradable copolymer fibers. Polymer, 2005, 46: 751-760

Acknowledgements This work was financially supported by the National Natural Science Foundation of China (21634006 and 51827803), and the National Key Research and Development Program of China (2017YFB0309001).

Author contributions Wu WS designed and synthesized the monomer, performed the experiments and tests, analyzed the results and prepared the manuscript with support from Wang XL; Wang XL and Wang YZ proposed the project and offered critical comments on the manuscript; Duan PH and Wang YL provided comments on the manuscript. All authors contributed to the general discussion.

Conflict of interest The authors declare that they have no conflict of interest.
Supplementary information Experimental details and supporting data are available in the online version of the paper.

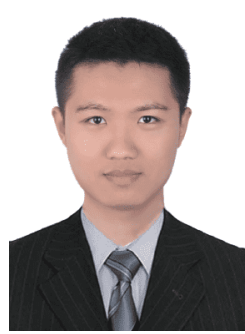

Wan-Shou Wu is a PhD student at Sichuan University under the supervision of Prof. YuZhong Wang. His research interest is flame retardant polyester materials.

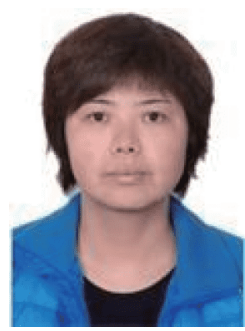

Xiu-Li Wang is currently a full professor at the College of Chemistry, Sichuan University. She earned her $\mathrm{PhD}$ degree in materials science (2003) and MSc degree in polymer chemistry and physics (1999) from Sichuan University, and BSc degree in chemistry (1994) from Sichuan University. In 2002, she joined Prof. Yu-Zhong Wang's group and her current research interests are focused on the synthesis, structure and properties of flame-retardant materials.

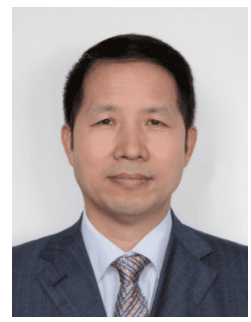

Yu-Zhong Wang earned his $\mathrm{PhD}$ degree from Sichuan University in 1994, where he was promoted to a full Professor in 1995. He is the Director of the National Engineering Laboratory for Eco-Friendly Polymeric Materials (Sichuan). His research interests are focused on fire-retardant and functional polymeric materials, bio-based and biodegradable polymers. He has been awarded eleven National and Provincial Science \& Technology awards. In 2015, he was selected as an Academician of Chinese Academy of Engineering.

\section{新型含苯并咪唑结构磺酸盐构建高火灾安全性热 塑性聚酯}

吴万寿, 段平慧, 王寅龙, 陈力, 汪秀丽 ${ }^{*}$, 王玉忠 ${ }^{*}$

摘要 热塑性聚酯本身具有极高的易燃性, 同时在燃烧过程中还会 产生浓烟以及严重的熔滴, 这已经成为阻碍其广泛应用的主要因 素. 为了解决这个问题, 在本文中, 我们合成了一种全新的含磺酸 盐以及苯并咪唑结构的离子单体, 并将其引入聚对苯二甲酸乙二 醇酯(PET, 热塑性聚酯模型) 分子链中. 由于离子聚集以及炭化能 力的协同作用, 共聚酯在高温下表现出极高的熔体黏度以及优异 的成炭能力. 当离子单体引入量为 $8 \mathrm{~mol} \%$ 时, 共聚酯能够通过UL $-94 \mathrm{~V}-0$ 级, 在测试过程中没有熔滴产生. 同时, 极限氧指数(LOI) 高 达 $33.0 \mathrm{vol} \%$. 与PET相比, 共聚酯的总产烟量, 峰值热释放速率以及 最大CO释放速率分别降低了 $45.2 \%, 60.5 \%$ 和 $75.0 \%$. 除此之外, 共聚 酯具有可纺性, 同时阳离子染料的竭染率也由PET的 $6.5 \%$ 提高到 $99.6 \%$, 表明共聚酯与阳离子染料之间具有很好的亲和性. 这种本 征阻燃的共聚酯在阻燃织物、艺术品基材、轨道交通与运输的装 饰材料方面都有很好的应用前景. 